\title{
Questions about Ki67 staining in luminal breast cancer
}

\author{
Kadri Altundag ${ }^{1}$
}

Received: 5 September 2017 / Accepted: 18 September 2017/Published online: 27 September 2017

(C) Springer Science+Business Media, LLC 2017

To the Editor,

I wish to congratulate Gallardo and colleagues for their article [1], in which they evaluated the prognostic significance of Ki67 and aimed to determine the most accurate prognostic cut-off. They found that the prognosis of luminal breast carcinoma can be predicted using Ki67 as a continuous variable and a standard cut-off value of $14 \%$. It was reported that interlaboratory reproducibility of Ki67 was moderate. Although central staining demonstrated a better intraclass correlation coefficient of 0.7 , in the setting of local staining, the intraclass correlation coefficient was low, i.e., 0.59 [2]. Furthermore, the National Comprehensive Cancer Network Clinical Practice Guidelines in Oncology do not recommend testing Ki67 routinely [3]. Therefore, Ki67 staining is not routinely carried out as a standard practice due to its inefficient reproducibility and insufficient recommendation other than for the purpose of clinical study.

\section{Compliance with ethical standard}

Conflict of interest Kadri Altundag has no conflicts of interest to declare.
Ethical approval This manuscript complies with the ethical rules applicable for this journal.

Human and animal rights This article does not contain any studies with human participants or animals performed by any of the authors.

\section{References}

1. Gallardo A, Garcia-Valdecasas B, Murata P, Teran R, Lopez L, Barnadas A, Lerma E (2017) Inverse relationship between Ki67 and survival in early luminal breast cancer: confirmation in a multivariate analysis. Breast Cancer Res Treat. doi:10.1007/ s10549-017-4486-z [Epub ahead of print]

2. Polley M-YC, Leung SCY, Mcshane LM, Gao D, Hugh JC, Mastropasqua MG, Viale G, Zabaglo LA, Penault-Llorca F, Bartlett JMS, Gown AM, Symmans WF, Piper T, Mehl E, Enos RA, Hayes DF, Dowsett M, Nielsen TO (2013) An International Ki67 reproducibility study. J Natl Cancer Inst 105:1897-1906

3. https://www.nccn.org/professionals/physician_gls/f_guidelines.asp. Accessed 04 Sep 2017

This letter to the editor refers to the article available at doi:10.1007/ s10549-017-4486-z and a rebuttal letter to this letter to the editor is available at doi:10.1007/s10549-017-4524-x.

Kadri Altundag

altundag66@yahoo.com

1 MKA Breast Cancer Clinic, Tepe Prime, Cankaya, Ankara 06800, Turkey 